Finance and Economics Discussion Series Divisions of Research \& Statistics and Monetary Affairs Federal Reserve Board, Washington, D.C.

\title{
A Nonlinear Look at Trend MFP Growth and the Business Cycle: Results from a Hybrid Kalman/Markov Switching Model
}

\section{Mark W. French}

2005-12

NOTE: Staff working papers in the Finance and Economics Discussion Series (FEDS) are preliminary materials circulated to stimulate discussion and critical comment. The analysis and conclusions set forth are those of the authors and do not indicate concurrence by other members of the research staff or the Board of Governors. References in publications to the Finance and Economics Discussion Series (other than acknowledgement) should be cleared with the author(s) to protect the tentative character of these papers. 


\title{
A Nonlinear Look at Trend MFP Growth and the business cycle: results from a hybrid Kalman/Markov Switching Model
}

\author{
Mark W. French
}

February 22, 2005

\begin{abstract}
The cycle in output and hours worked is not symmetric: it behaves differently around recessions than in expansions. Similarly, the trend in multifactor productivity (MFP) seems to pass through different regimes; there was an extended period of slow MFP growth from about 1973 through 1995, and faster growth thereafter. Typical linear models and linear filters such as the Kalman filter deal poorly with asymmetry and regime changes. This paper attempts to determine more accurately and quickly any shifts in trend MFP growth, using a nonlinear Kalman/Markov filter with a model of the unobserved components of output and hours. This hybrid model incorporates regime-switching in the business cycle and in the trend growth of MFP. Estimation results are promising. The hybrid model and associated filter appear to be faster than the basic Kalman filter in detecting turning points in the smoothed conditional mean estimate of trend MFP growth; in addition, the hybrid model avoids some of the Kalman filter's biases in reconstructing historical business cycles and the MFP trend.
\end{abstract}

Board of Governors of the Federal Reserve System

Division of Research and Statistics, Mail Stop 80

20th and Constitution Ave., NW

Washington, DC 20551

JEL CLASSIFICATION: C32, E32, O47

KEYWORDS: multifactor productivity, total factor productivity, regime switching, Markov switching

I would like to thank (without implicating) Chris Murray, Jeremy Piger, Bill Wascher, and participants at a Federal Reserve Board workshop for their helpful suggestions. 


\section{Summary}

Over the past two decades, researchers have accumulated evidence that the movement in U.S. economic output is not symmetric or linear. When one estimates linear models of U.S. output and productivity, neither the transitory nor the permanent shocks to output are distributed in smooth, normal fashion. ${ }^{1}$ There appear to be distinct periods of recession and rapid recovery, as in the "plucking" model of the business cycle (Friedman, 1993). NBER recessions have been qualitatively different from other cyclical shocks over the period 1960 through 2004: the drops in output during many of the seven NBER-identified recessions were too large to be consistent with traditional linear models of activity with normally distributed errors. Furthermore, the trend growth rate of multifactor productivity (and perhaps also GDP and labor productivity) appears to have fallen rather abruptly around 1973, and appears to have risen abruptly around 1995. To capture these asymmetries, this paper presents a nonlinear "regime-switching" model of output and multifactor productivity (MFP), and compares its estimates of the business cycle and trend MFP with the estimates from a similar linear model using the Kalman filter.

\section{Linear versus nonlinear trend-cycle decomposition}

Nonlinearities and asymmetry create difficulties for those attempting to filter trend from cycle in output and multifactor productivity. Linear filters such as the Kalman filter - and the corresponding linear unobserved-components (UC) models - are not designed to capture asymmetries or nonlinearity in trend and cycle. ${ }^{2}$ The linear UC/Kalman model presented (for purposes of comparison) in this study estimates rather large business cycle peaks in the 1960s and 1970s, because it must maintain symmetry between recessions and expansions - even though recessions in fact tend to be deeper (though shorter) than expansions. Furthermore, in response to the downward shock to the Solow residual in the early to mid-1970s, the smoothed Kalman estimate of trend drags out the deceleration in trend MFP all the way through 1981. The Kalman filter also overstates the ongoing volatility of trend MFP growth - to the point where the unsmoothed Kalman trend in MFP displays technological regress in the 1981/82 recession (similar to the downturn in level of Kalman trend described in French (2001)).

\footnotetext{
${ }^{1}$ See for example Neftci (1984), Hamilton (1989), Sichel (1989), Kim and Nelson (1998, 1999) among a multitude of others.

${ }^{2}$ These considerations show up as outlying residuals in the stochastic state equations (especially in 1973) of typical models using only the Kalman filter (including the linear model in Appendix B). 
However, the standard UC/Kalman methodology can be extended so that it is consistent with the above findings of asymmetry and nonlinearity. That is, the linear unobserved-components model and accompanying filter can be modified to allow for occasional recessionary regimes in the business cycle, and allow for rare, rapid shifts in trend growth of multifactor productivity. ${ }^{3}$

This paper presents such an extended unobserved-components model, embedding Markov switches into the standard linear UC/Kalman framework. ${ }^{4}$ This "hybrid" UC model and associated filter are very similar in general form to the linear UC/Kalman approach of French (2001) and Roberts (2001). The observed variables are output and hours worked (and the exogenous flow of capital services), and the extended model and filter incorporate several unobserved components: the trend in MFP and cycles in hours and output. But, in addition, the hybrid Kalman/Markov UC model includes an additional regime-switching term to capture the depth of business cycle recessions and the rapid recovery phase which usually follows. ${ }^{5}$ In addition, the hybrid equation for trend MFP growth includes a switch to reflect a "fast-MFP-growth regime" or "slow-MFP-growth regime". This switch replaces the UC/Kalman model's assumption of normally distributed shocks to trend MFP growth.

\section{A generic trend-cycle decomposition of output, hours and MFP}

A variety of models and filters have been used to estimate unobserved trend in multifactor productivity (MFP). Most of them are encompassed by the general specification in French (2001), summarized in the following bullet points:

\footnotetext{
${ }^{3}$ Two regimes in trend growth are allowed in this model. Of course, there may be more; however the model takes account of this possibility to a certain extent by calculating a conditional mean estimate of trend growth that lies between the fast-growth and slow-growth regimes.

${ }^{4}$ For comparison with this extended nonlinear model, I also estimate a linear unobserved components/Kalman model (described in appendix B), with no regime switching.

${ }^{5}$ The switch equals 1 in recessionary regimes, and 0 at other times. Estimated "transition probabilities" show the ex ante likelihood of switching from one regime to another. The coefficient of the switch reflects the size of the downward "pluck" to activity in full-scale recessions. When the switch reverts back to zero, an estimated "rapid recovery" phase begins. All the recessionary regimes estimated by the model occur during NBER-dated recessions. However, a few NBER recessions are not deep enough for the hybrid switching model/filter to distinguish them with complete confidence from non-recessionary dips.

Chib and Dueker (2004) extend this framework, allowing for time-varying size and duration of pluck. However, their approach is not necessarily an improvement, since its estimates are imprecisely measured -- in practice requiring many indicator variables to identify the changes in size and duration of the pluck.
} 

- $\quad$ Nonfarm business output $(\mathrm{Q})$ is the product of trend $\left(\mathrm{Q}_{\text {trend }}\right)$ and gap $\left(\mathrm{Q}_{\text {cycle }}\right)$.
- Hours supplied $(\mathrm{H})$ is the product of trend hours supplied $\left(\mathrm{H}_{\text {trend }}\right)$ and a stationary cyclical term $\left(\mathrm{H}_{\text {cycle }}\right)$.
The hours cycle $\left(\mathrm{H}_{\text {cycle }}\right)$ reflects the output cycle to some extent $\left(\mathrm{Q}_{\text {cycle }}\right.$ factor loading $)$ but also includes an idiosyncratic component $\left(\mathrm{H}_{\text {idiosync }}\right)^{6}$
Trend labor $\left(\mathrm{L}_{\text {trend }}\right)$ is the product of trend hours supplied $\left(\mathrm{H}_{\text {trend }}\right)$ and the quality of each labor hour $\left(\mathrm{L}_{\text {qual }}\right)$.
A two-factor Cobb-Douglas production function holds in equilibrium. ${ }^{7}$
The observed Solow residual (S) is defined to be nonfarm business output divided
by a weighted average of inputs to production, with weights equal to long-run average income shares of labor and capital.

Together, these six bullet points imply that the observed Solow residual is the product of trend in multifactor productivity $\left(\mathrm{MFP}_{\text {trend }}\right)$ and a combination of cyclical factors $\left(\mathrm{Q}_{\text {cycle }}, \mathrm{H}_{\text {idiosync }}\right)$. The bullet points are restated in equations $1-6$ :
(1) $\mathrm{Q}=\mathrm{Q}_{\text {trend }} * \mathrm{Q}_{\text {cycle }}$
(2) $\mathrm{H}=\mathrm{H}_{\text {trend }} * \mathrm{H}_{\text {cycle }}$
(3) $\mathrm{H}_{\text {cycle }}=\mathrm{Q}_{\text {cycle }}$ factor loading $* \mathrm{H}_{\text {idiosync }}$
(4) $\mathrm{L}_{\text {trend }}=\mathrm{H}_{\text {trend }} * \mathrm{~L}_{\text {qual }}$
(5) $\mathrm{Q}_{\text {trend }}=\mathrm{MFP}_{\text {trend }} * \mathrm{~L}_{\text {trend }}{ }^{\alpha} \quad * \mathrm{~K}^{1-\alpha}$
(6) $\mathrm{S}=\mathrm{Q} /\left[\left(\mathrm{H}^{*} \mathrm{~L}_{\text {qual }}\right)^{\alpha} * \mathrm{~K}^{1-\alpha}\right]$

Equations 1 to 6 are "observation equations". They link the observed variables, output and hours worked, with their unobserved components: the output cycle, the hours cycle, and the trend in

\footnotetext{
${ }^{6}$ Here, the "factor loading" is an exponent showing the fraction of growth in the output cycle that also appears as growth in the hours cycle. The multivariate Kalman specifications mentioned on pages 2 and 13 of French (2001) did not subdivide the hours cycle in this way, but instead incorporated a very large cross-correlation between the hours cycle and the output cycle. The current model's subdivision of the hours cycle is almost exactly equivalent, but makes more manageable the incorporation of business-cycle switching.

${ }^{7}$ The measure of nonfarm business output is the BLS published measure, as defined in appendix A. Labor quality is taken to be exogenous; likewise, the capital stock is assumed given. For this exercise, I used the BLS capital-stock series, interpolated to a quarterly frequency, as described in Appendix A. Also, I have used an equilibrium labor share of 70 percent, similar to the long-run average of the series over history.
} 
MFP. ${ }^{8}$ These observation equations are very similar to those in the hybrid regime-switching model of Section IV and in the linear Kalman model of Appendix B. In addition, both the hybrid state-space model and the linear alternative include "state" equations describing the evolution of the output cycle, the hours cycle, and the trend in MFP. (The different state equations distinguish the regime-switching hybrid model from the UC/Kalman model.) Together, the observation equations and the state equations constitute a "state-space" model. Such state-space models can be linear or nonlinear. The UC/Kalman model in Appendix B is linear, while regime-switching makes the hybrid Kalman/Markov model of Section IV nonlinear.

To get from the generic observation equations (1-6) to the full state-space models presented later, I had to pretest the behavior of the trend in hours worked (from equation 2), to see whether it fit better into a Kalman or Markov framework. Then given an approach to the trend in hours worked, I had to find the best available model to capture the nonlinear behavior of output and MFP trend. These issues are discussed in Section III.

\section{How nonlinearities and asymmetries affect the choice of filtering technique}

\section{Estimation of trend hours}

As mentioned above, traditional Kalman filtering assumes that shocks to trend growth rates are normally distributed, and thus that trend growth rates evolve smoothly. As noted in the introduction, this is a bad assumption for trend MFP. In contrast, the Kalman trend in hours worked is better-behaved than the Kalman trend in MFP in that it does not have the large outliers found in estimated MFP trend. This suggests that the Kalman assumption of a smoothly evolving trend growth rate seems more reasonable for hours than the Markov assumption of occasional large breaks in trend growth, and so, in this paper, I preestimate the trend supply of hours in a Kalman framework. In particular, the working age population is assumed to be exogenous, and the various

\footnotetext{
${ }^{8}$ Equations 1 - 6 imply the following relationship between the observed Solow residual and the underlying trend in multifactor productivity:

(7) $\mathrm{S}=\left[\mathrm{Q}_{\text {cycle }}^{\left.1-\alpha * \text { factor loading } / \mathrm{H}_{\text {idiosync }}{ }^{\alpha}\right] * \mathrm{MFP}_{\text {trend }}}\right.$

The objective is to extract $\mathrm{MFP}_{\text {trend }}$, the unobserved trend in multifactor productivity shown in equation 7 , from the Solow residual. In French (2001), the variables in brackets in equation 7 above were combined into a single cyclical term; this allowed univariate filtering of the Solow residual in equation 7 via alternate methods: Kalman or Markov switching. In contrast, the current study is multivariate. It does not collapse equations 1 to 6 into one reduced-form equation like equation 7; rather, the identities in equations 1 through 6 are explicitly included.
} 
components of the trend hours/population ratio (including trend participation rate, NAIRU, workweek, etc.) are estimated with the help of the Kalman filter. The resulting estimate of trend hours worked is then treated as an exogenous input into the hybrid Markov-switching model. The hours cycle corresponding to this estimated hours trend comfortably passed an augmented DickeyFuller test for stationarity.

\section{Improvements in switching models as an alternative to basic Kalman filtering}

In general, Markov-switching models can smoothly handle nonlinearities such as those associated with an asymmetric business cycle or infrequent shocks to trend MFP. However, Hamilton's original Markov model (1989) is not well-suited to the task. Although his model can identify breaks in trend and phases of the business cycle, it explicitly excludes the possibility of transitory shocks to the level of output. A superior alternative is the hybrid Kalman/Markov model developed by Kim and Nelson $(1998,1999)$. Their univariate model is almost identical to the standard Kalman model, except that Markov switches are added to the equations for the cycle and for the trend growth rate. The form of their switch in the cycle allows for the possibility of the three-phase plucking model of the business cycle, which was supported by several studies in the 1990s.

However, further improvements can be made to Kim and Nelson's univariate hybrid Kalman/Markov model. Kim and Murray (2002) incorporated additional measures of activity, using extra information to better separate common trend from the common cycle in four monthly indicators of activity. I selected their generic multivariate hybrid Kalman/Markov approach to model trend in quarterly MFP and the cycle in output and hours. ${ }^{9}$

\footnotetext{
${ }^{9}$ Kahn and Rich (2003) attempt to use the same multivariate switching methodology to distinguish trend and cycle in labor productivity. However, though MFP seems to be stationary around a broken trend, the capital deepening component of labor productivity is not; thus, labor productivity should not be modeled simply as a switching process. Second, that paper assumes that because equilibrium growth is 0 for the capital/labor ratio, the labor share, and the saving rate, the in-sample movement of these three great ratios is also zero at "trend" frequencies (those lower than the business cycle) - a counterfactual assumption. Finally, the paper assumes that productivity and compensation per hour lead hours worked and consumption by three quarters. Yet in fact, changes in consumption and output (per hour) generally occur almost simultaneously, short-run changes in output lead hours by about a month, and compensation per hour responds to productivity changes with a long lag.
} 


\section{State-space specification of the hybrid model}

Trend-cycle decomposition corresponds to a type of unobserved components model, typically representable in "state-space" form. My state-space model structure is as follows:

\section{Observation equations}

1. Log change in nonfarm business output $=$ growth of MFP trend

+ wtd av of growth in trend hours worked and growth in inputs of capital services + change in output cycle

2. Log change in observed hours $=$ growth in trend hours + change in idiosyncratic component of hours cycle + factor loading * change in output cycle

\section{State equations}

1. Growth in trend for MFP $=\mathrm{a} 0 \quad-\mathrm{a} 1 *$ (Switch 1 [=1 in slow trend growth regime $])$ + transitory shock to trend growth rate of MFP

2. Output cycle $(\mathrm{t})=\mathrm{b} *$ output cycle $(\mathrm{t}-1)+\mathrm{c} * \Delta$ output cycle $(\mathrm{t}-1)$

$+\mathrm{d} *($ Switch $2[=1$ in recession $])+$ shock to output cycle

3. Idiosyncratic comp. of hours cycle $(\mathrm{t})=\mathrm{f} *$ idiosync. comp. $(\mathrm{t}-1)+$ idiosyncratic shock

The covariance between the shock to the idiosyncratic hours component and the shock to the output cycle is zero by construction.

This hybrid UC specification is similar to the standard UC/Kalman model of Appendix B, except that the hybrid model incorporates multivariate switching. For each switch, there are four "transition probabilities". For example, the business cycle has four possible transitions in state: from expansion to expansion, expansion to recession, recession to expansion, and recession to 
recession. Similarly, the trend in MFP can either remain in the slow growth regime, remain in the high growth regime, or switch regimes (in either direction). The hybrid model and filter estimate an ex ante probability for each of these possible transitions. Given these transition probabilities and the observed data on hours and output, the hybrid Kalman/Markov filter assigns a probability that the economy is in expansion (or recession), and a probability that the economy is in a fast trend MFP growth (or slow trend MFP growth) regime. In essence, the estimated path for the output cycle and the trend in MFP is a probability-weighted average of the state of the economy in each of the four regimes. This weighted averaging makes the conditional mean estimate of the trend growth rate of MFP less bumpy than one might expect from the presence of regime switches.

\section{Results and comparison with the linear Kalman model of Appendix B}

The estimated parameters of the hybrid model, based on a sample from 1960:Q1 - 2004:Q2, are shown in Table 1. ${ }^{10}$ Especially noteworthy are the size and significance of the "plucking" parameter, and the low transition probability for continuation of recessions. In particular, the ex ante probability of continued recession is relatively low at 30 percent, and the size of large recessionary plucks to output can be as much as 7 percent at an annual rate. These two estimated parameters are an important measure of the nonlinearity and asymmetry of the business cycle.

\section{Hybrid model estimate of trend MFP growth}

Figure 1a shows the hybrid model's ex post ( smoothed $\left.^{11}\right)$ estimate of the trend growth rate of MFP. This estimated growth rate ranges from more than 1.6 percent in the early 1960s to a low of less than 0.7 percent around 1980, with noticeable turning points in 1963, 1982 and 1995. Figure $1 \mathrm{~b}$ focuses on trend growth in the recent past: For 2004Q2, the hybrid filter's conditional mean estimate of trend MFP growth was about 1.4 percent, compared with actual MFP growth of 2.7 percent.

\footnotetext{
${ }^{10}$ The estimates were generated using a modified version of software kindly provided by Chris Murray. See Kim and Murray (2002) for a description of the solution algorithms.

${ }^{11}$ A hybrid "smoother", akin to the Kalman smoother, generates the ex post "smoothed" estimates of the hybrid model's state variables (Kim and Murray 2002). Such smoothers use the full sample, after the fact, rather than just the data available in real time, to estimate the state - thus such smoothed estimates are sometimes referred to as "two-sided".
} 


\section{TABLE 1}

Coefficients of the state equations

Parameter Standard error

a0 (trend growth rate of MFP in the high-growth regime)

$1.9 \%$

al (difference between trend growth in high- vs low-growth regimes) $1.2 \%$

b (coefficient of lagged dependent variable in output cycle equation) $\quad .94$

c (coefficient of $\Delta$ lagged dependent variable in output cycle equation) $\quad-.55$

$\mathrm{d}$ (size of "pluck" in unusually deep recession quarters, annual rate) $\quad-7.3 \%$

e (response ["factor loading"] of hours cycle to output cycle) $\quad .90$

$\mathrm{f}$ (coefficient of lagged dependent variable in the equation for $\quad .92$

idiosyncratic component of hours cycle)

mean growth of measured MFP over the full sample (annual rate) $\quad 1.04 \%$

Variability of shocks to the state equations

standard deviation of permanent one-time shocks to MFP (a.r.)

std dev of shocks to output cycle equation (a.r.)

std dev of shocks to equation for idiosyncratic part of hours cycle (a.r.) 0.78
Parameter Standard error

\section{Transition probabilities}

prob(continuation of fast trend growth regime) $=$ prob(continuation of slow trend growth regime) $=$ prob(continuation of cyclical expansion) = prob(continuation of recession)
Parameter Standard error

$97.8 \%$

$98.2 \%$

$97.9 \%$

$(24.6 \%)$ 


\section{Estimates of the business cycle}

Figure 2 a shows the ex post estimated probability that the economy is in a business-cycle downturn too large to be consistent with a symmetric linear model. (NBER business-cycle turning points are marked by the vertical lines.) As can be seen, strong upturns in that probability are evident in all of the NBER recessions, and the probability exceeds 50 percent for 4 of the 7 NBER recessions. Thus, Figure 2 indicates that according to the hybrid model, only the recessions of 1960, 1990/91 and 2001 would be consistent with a symmetric linear model. Less importantly, Figure 2 also shows that, ex post, the hybrid model assigns virtually zero probability to the presence of any business-cycle downturns not cited by the NBER.

Figure $2 \mathrm{~b}$ shows the estimated size and timing of recessionary "plucks", and the rapid-recovery period during which that pluck goes away. The timing of the rapid recovery periods matches up closely, by and large, with the quarters immediately following the NBER troughs. Figure $2 b$ also suggests that the drop in output and hours in 1974Q4, 1975Q1, 1980Q2 and 1982Q1 was far too large to be consistent with a model in which all recessionary quarters are qualitatively the same as other cyclical downturns or upturns in output and hours. Figure $2 \mathrm{~b}$ can be read as confirmation that the data for output and hours appear consistent with Friedman's asymmetric plucking model of the business cycle.

Figure 3 compares the estimates of the business cycle from the hybrid model with those from the linear Kalman filter model of Appendix B. The cycle from the hybrid model is more frequently negative than is the cycle from the linear Kalman model - a consequence of the regime switch in the hybrid model that generates an asymmetric "plucking" effect on the cycle. The assumption of symmetric cycles in the linear Kalman model causes it to estimate much higher peaks in activity in the 1960s and 1970s than does the hybrid model.

\section{Comparison of estimates of the trend in MFP.}

Figure 4 compares ex-post smoothed estimates of trend MFP growth from the hybrid and the UC/ Kalman models. For the UC/Kalman model, smoothed trend MFP growth ranged from 1.8 percent in the early 1960s to 0.3 percent in 1981 . Growth rates from the hybrid model were a bit less wideranging-from 1.6 percent in the early 1960s to a low of 0.7 percent about 1980 . 
For the last quarter in the sample (2004Q2), both the hybrid model and the UC/Kalman model estimated trend growth rate of MFP at 1.4 percent, compared with actual reported MFP growth of 2.7 percent. This end-of-sample deviation of UC/Kalman trend from actual growth of the Solow residual is a bit surprising; in earlier periods, the unsmoothed Kalman filter typically treated a big chunk of cyclical shocks as trend shifts. Regime-switching models tend to be more conservative in shifting the estimated trend growth rate - though the hybrid model in this paper seems more responsive than the early Hamilton switching model tested in French (2001).

In addition, Figure 4 indicates that the linear Kalman filter produced a very simple evolution in the trend growth rate of MFP: a steady decline from the mid-1960s through 1981, and a steady increase thereafter. ${ }^{12}$ An unattractive feature of the UC/Kalman trend in growth is that there is no qualitative change in behavior of MFP from 1995 on, relative to behavior in the previous decade. In contrast, the hybrid switching model generates a trend growth rate that falls through 1979, remains at a low level through 1995, and then picks up substantially. Figure 4 also shows small peaks and valleys in the conditional mean estimate of hybrid MFP trend growth (even after smoothing), implying that a small fraction of business-cycle shifts in activity are permanently passed into the level of MFP [a result also found by Kim and Murray (2002)].

Figure 5 compares the unsmoothed ex ante estimates with the ex-post smoothed estimates of the trend growth rate of MFP, using the UC/Kalman model. Similarly, Figure 6 shows pre- and postsmoothing trends for the hybrid model. The two charts give an idea of the robustness (or lack of robustness) of the ex ante estimates of levels and turning points in trend MFP growth for the two filtering methods.

Figure 5 illustrates two problematic aspects of the estimates of trend MFP from the linear UC/Kalman model. First, the unsmoothed Kalman trend growth rate is negative in the 1981 recession, implying technological regress. Second, unsmoothed estimates of trend MFP growth in the linear UC/Kalman model showed a large and persistent bias relative to the ex post estimate of trend growth after Kalman smoothing. The unsmoothed UC/Kalman filter estimate persistently

\footnotetext{
${ }^{12}$ Changes in the linear UC/Kalman specification can sometimes noticeably affect the Kalman estimate of trend. However, the properties of the UC/Kalman model described here are fairly typical of a variety of UC/Kalman specifications.
} 
overestimated growth from 1965 through 1980, and persistently underestimated trend growth from 1982 onward. As shown in Figure 6, the ex ante bias for the hybrid model from 1965 to 1975 was noticeably smaller. For the period from 1982 through 2005, the unsmoothed hybrid estimate of trend was biased - but the bias was not uniformly negative, like that of the unsmoothed $\mathrm{UC} /$ Kalman estimate in Figure 5.

Speed in catching turning points in trend MFP growth.

An important goal in estimating MFP trends is to diagnose turning points in the trend growth rate as soon as possible - preferably within a year or so. The unsmoothed hybrid Kalman/Markov model appears to diagnose changes in trend MFP growth rather quickly, faster than the corresponding unsmoothed Kalman model. Figure 6 shows that for the multivariate hybrid switching model, unsmoothed (one-sided) estimates of the trend growth rate lagged smoothed (two-sided) estimates by only about 2-1/2 quarters, on average. Most importantly, that lag was rather short after the major turning points in 1963, 1982 and $1995 .{ }^{13}$ Figure 5 showed that the unsmoothed estimates from the linear UC/Kalman model in Appendix B did not pick up the ex post smoothed turning points (in 1963 and 1982) until 5 to 17 quarters had passed. ${ }^{14}$

Figure 7 shows the hybrid model's ex ante (unsmoothed) and ex post (smoothed) estimates of the probability that the economy was in a low-trend-growth regime for each quarter from 1960 through 2004. The ex post probability of a downward regime shift moved above 50 percent in 1973 , close to the commonly-accepted date of the productivity slowdown, and moved back down to below 50 percent in 2000, a bit later than the commonly accepted date of the productivity acceleration. Also worth noting in Figure 7: the hybrid model gave only two false positive signals of a switch to the low trend growth regime - in 1960 and 1970.

\footnotetext{
${ }^{13}$ Less importantly, the unsmoothed hybrid trend growth rate was prompt in picking up the (small) effects of business cycles on trend MFP growth, as in 1970 and 1974/75 (Figure 6).

${ }^{14}$ Both the hybrid model and the multivariate UC/Kalman model, however, are deceptively quick in identifying shifts in trend MFP growth, because both used an externally estimated exogenous trend in hours. A less impressionistic horse race would involve monte carlo estimation of parameters and states of each model, but with endogenous estimates of the hours cycle. However, this exercise would be extremely time-consuming.
} 


\section{Conclusions}

This paper uses a nonlinear hybrid Kalman/Markov model to estimate trend MFP growth and compares the the results from this model with the standard linear Kalman filter approach used elsewhere in the literature. The estimated parameters of the hybrid model suggest strongly that the business cycle is nonlinear, with four out of the last seven NBER recessions too large to fit comfortably into a symmetric linear Kalman framework. This evidence can be read as confirmation that the data for output and hours appear consistent with Friedman's plucking model of the business cycle.

In addition, the results suggest that the hybrid model may provide better estimates of trend MFP than does the traditional Kalman filter. In general, the hybrid model appeared faster than the linear Kalman model in detecting turning points in trend MFP growth, and, if there was a marked upturn in trend MFP growth in 1995, that upturn is better captured by the hybrid switching model than by the UC/Kalman model. However, more formal proof of the superior performance of this multivariate hybrid model will require implementing a rolling monte carlo estimation and simulation of the hybrid and linear Kalman models, a topic for future research. ${ }^{15}$

\footnotetext{
${ }^{15}$ Univariate monte carlo comparisons of hybrid versus UC/Kalman trends in MFP would be less time consuming. Morley and Piger (2004) did a univariate monte carlo linear-versus-nonlinear comparison for the cycle in GDP. 


\section{Appendix A: Data definitions}

Data in this paper are essentially the same as used in French (2001), updated to include data from the first quarter of 1959 through the second quarter of 2004. Data for almost all variables used in the above analysis were taken from quarterly and annual publications by the Bureau of Labor Statistics (BLS). However, the estimates used here do not include new or revised BLS data published from December 2004 onward.

\section{Labor quality}

Quality-adjusted hours data (hours of all private nonfarm workers excluding government enterprises) were taken from raw data published by the BLS. ${ }^{16}$ The quality-adjusted hours data were then divided by the unadjusted hours data to get an index number representing "labor quality". The index number was extrapolated forward based on the growth of the factor over the last historical year where adjusted BLS data are available (that is, 2001). In the work described above, I have treated the historical data series for labor quality as an exogenous variable.

\section{Capital services}

Data on capital services were generated as follows. Annual capital stock data produced by the BLS (available through 2001) were interpolated to a quarterly frequency. Then the quarterly capital stock estimates were extended forward on the basis of quarterly investment data since 2001. In addition, the BLS capital stock data were revised backward from 2001 to reflect the BEA comprehensive revisions of 2004.

The BLS defines private nonfarm business capital stock very broadly to include equipment, structures, inventories and land. The (Tornqvist) aggregate of these variables differs crucially from the BEA aggregate in that BLS uses rental rates of capital to chain-aggregate, while BEA uses prices to chain-aggregate. This difference matters when data on nonresidential

\footnotetext{
${ }^{16}$ The BLS quality adjustment of labor hours involves Tornqvist-weighting of the hours of different classes of workers, based on their share of total labor compensation. Tornqvist aggregation is similar to Fisher-aggregation in many ways: both have "ideal", "superlative" properties. The Tornqvist index averages a sector's weight in successive periods before taking a weighted geometric average of quantity growth in the various sectors, while the Fisher index aggregates growth across sectors with one period's weights (Laspeyres), then with the next period's weights (Paasche), and then geometrically averages the two aggregates. The Fisher index is exact assuming unitary elasticity of substitution among sectors (Cobb-Douglas), while the Tornqvist index is best for the more general Translog setup. In practice, this difference in methodology is probably not the most important cause of differences between the BEA and BLS aggregates.
} 
structures (which have relatively low depreciation rates and thus low rental rates relative to price) are combined with data on equipment (which has high depreciation rates and thus high rental rates relative to price). Because the stock of equipment has grown faster than the stock of nonresidential structures, the BLS capital stock increases faster than the BEA capital stock. Also, the BLS assigns higher weights to computers than to other equipment compared with the BEA aggregate equipment data. This difference in weights also affects the estimated growth of the stock of equipment. The BLS approach is a theoretically preferred "service flow" approach to estimating an aggregate capital input to the production function. The BLS use of rental rates has a practical advantage as well: the resulting faster growth of estimated capital stock reduces the size of the Solow residual in the BLS estimates.

The BLS measure of aggregate capital differs from most in that it includes land. In this study, the real value of the stock of land for recent quarters is based on its average growth rate over the last three years of available data.

\section{Nonfarm business output}

Data on output were taken from the BLS. (The BEA measure assigns zero labor productivity growth in government enterprises, which is not an acceptable assumption for studies of productivity.) In contrast to the BEA definition, the BLS output definition excludes output of government enterprises: the resulting measure is called "private nonfarm business output". The BLS releases data for this narrower measure in the productivity and cost release, twice quarterly, shortly after the advance and preliminary GDP releases. ${ }^{17}$

\footnotetext{
${ }^{17}$ Second-revision data on nonfarm output are published in the first productivity and cost release for the following quarter -- i.e., with a month delay. 


\section{Appendix B. State-space specification of the Kalman model without switching}

The structure of the comparison model (without regime-switching) is as follows:

\section{Observation equations}

1. Log nonfarm business output $=\log$ NFB output cycle $+\log$ MFP trend $+\log$ of geometrically wtd av of trend hours worked and inputs of capital services

2. Log observed hours worked $=\log$ hours trend $+\log$ hours cycle

State equations

1. trend for $\mathrm{MFP}=$ trend for $\mathrm{MFP}(\mathrm{t}-1)+$ trend growth rate of MFP

2. trend growth rate of MFP $=$ trend growth rate of $\mathrm{MFP}(\mathrm{t}-1)+$ shock

3. Output cycle $(\mathrm{t})=\mathrm{a} *$ output cycle $(\mathrm{t}-1)+\mathrm{b} * \Delta$ output cycle $(\mathrm{t}-1)+$ shock

4. Hours cycle $(\mathrm{t})=\mathrm{c} *$ hours cycle $(\mathrm{t}-1)+\mathrm{d} * \Delta$ hours cycle $(\mathrm{t}-1)+$ shock

This pure linear UC/Kalman specification is almost identical to the hybrid specification of section IV, but without switching. The two differences are:

- the hours cycle is not decomposed into an idiosyncratic component and a component tracking the business cycle in output, as was necessary in the hybrid model for technical reasons. Instead, shocks to the overall hours cycle are allowed to covary with shocks to the output cycle. 
The I(1) shocks to MFP trend have been omitted from the Kalman version. The reason is that maximum likelihood estimation of the Kalman model has difficulty distinguishing cyclical shocks from permanent one-time shocks to the level of trend. When I(1) shocks were included in the model, they soaked up too much of the overall variance of output. The behavior of the I(1) shocks was not acceptable: their sum was clearly stationary, rather than following the specified random walk. In effect, the so-called "I(1)" component was in fact mean-reverting and stationary, creating a saw-tooth pattern in trend level of MFP. Omission of the I(1) shocks also reduced the tendency of the Kalman model to display technological regress in the MFP trend.

\section{Parameter estimates for the linear Kalman model}

The estimated parameters, based on a sample from 1960:Q1 - 2004:Q2, are

\section{Coefficients of the state equations}

b (coefficient of lagged dependent variable in output cycle equation) $\quad .91$

c (coefficient of $\Delta$ lagged dependent variable in output cycle equation) $\quad .21$

$\mathrm{d}$ (coefficient of lagged dependent variable in equation for hours cycle) .96

e (coefficient of $\Delta$ lagged dependent variable in hours cycle equation) $\quad .44$

Variability of shocks to the state equations

standard deviation of shocks to trend growth of MFP (annual rate) $\quad .03 \%$

std dev of shocks to output cycle equation (annual rate)

std dev of shocks to equation for hours cycle (annual rate)

cross-correlation between shocks to hours cycle \& output cycle
Parameter Standard error

$.81 \%$

$.99 \%$

.77 


\section{REFERENCES}

Chib, Siddhartha and M. Dueker (2004), "Non-Markovian Regime Switching with Endogenous States and Time-varying State Strengths", Federal Reserve Bank of St. Louis working paper 2004-030a, November.

French, Mark (2001), "Estimating Changes in Trend Growth of Total Factor Productivity: Kalman and H-P filters Versus a Markov-Switching Approach", Federal Reserve Board Finance and Economics Discussion Series \#2001-44, September.

Friedman, Milton (1993), “The 'Plucking Model' of Business Fluctuations Revisited”, Economic Inquiry, April, pp. 171-177.

Hamilton, James (1989), "A New Approach to the Economic Analysis of Nonstationary Time Series and the Business Cycle", Econometrica, Vol. 57, pp. 357-384, March.

Kahn, James and R. Rich (2003), "Tracking the New Economy: Using Growth Theory to Detect Changes in Trend Productivity", Federal Reserve Bank of New York Staff Reports no. 159 , January.

Kim, Chang-Jin and C. Murray (2002) "Permanent and Transitory Components of Recessions", Empirical Economics.

Kim, Chang-Jin and C. Nelson (1998), "Business cycle turning points, a new coincident index, and tests for duration dependence based on a dynamic factor model with regime switching", Review of Economics and Statistics Vol 80 pp. 188-201.

Kim, Chang-Jin and C. Nelson (1999), "Friedman's plucking model of business fluctuations: Tests and estimates of permanent and transitory components", Journal of Money, Credit and Banking, Vol. 31, pp. 317-334.

Morley, James and J. Piger (2004), "The Importance of Nonlinearity in Reproducing Business Cycle Features", Federal Reserve Bank of St. Louis working paper 2004-032A, November.

Neftci, Sali (1984), “Are Economic Time Series Asymmetric over the Business Cycle?”, Journal of Political Economy, pp. 307-328.

Roberts, John M. (2001), "Estimates of the Productivity Trend Using Time-Varying Parameter Techniques", Contributions to Macroeconomics Volume 1 no. 1.

Sichel, Daniel (1989), “Are Business Cycles Asymmetric? A Correction”, Journal of Political Economy, pp. 1255-1260. 


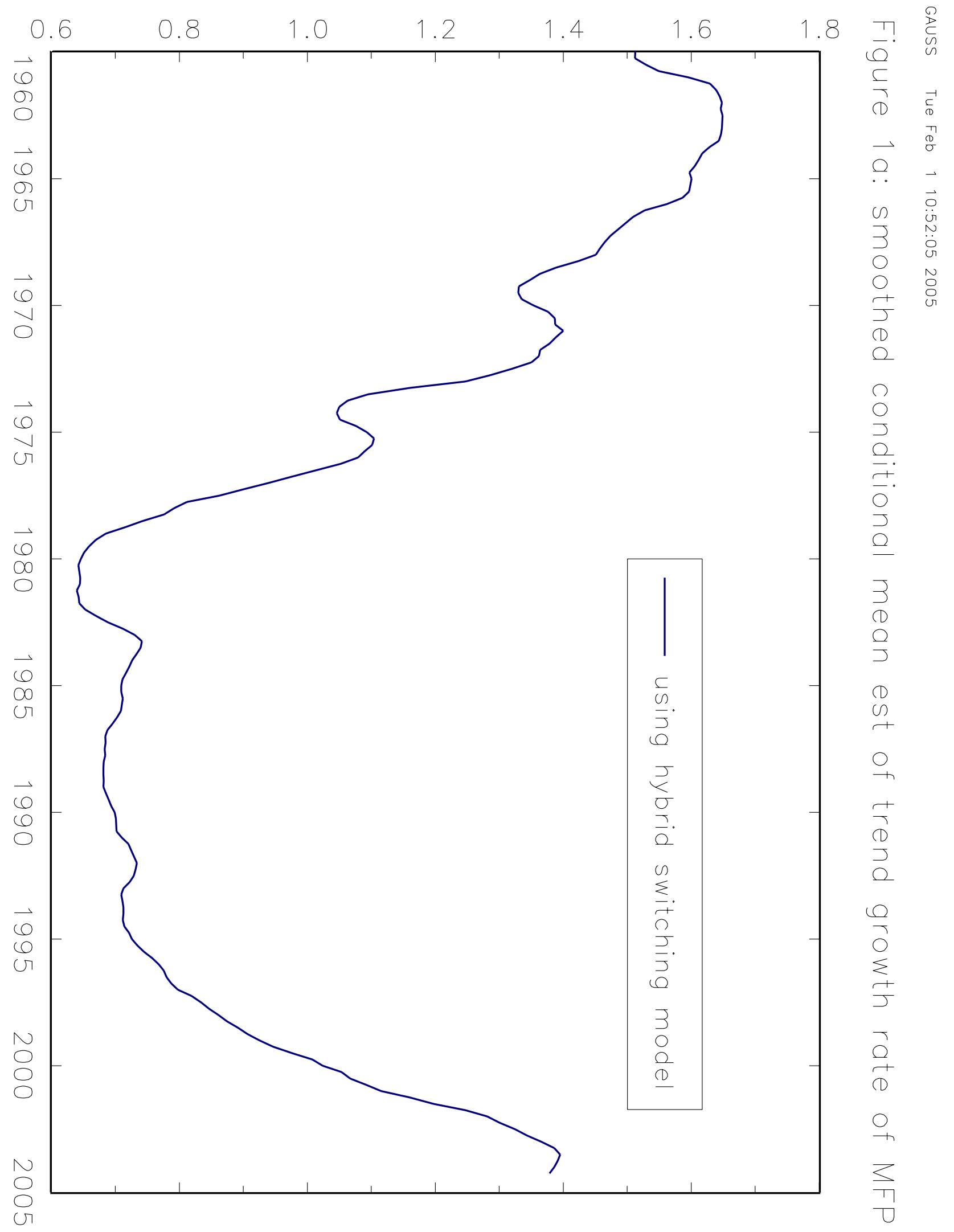




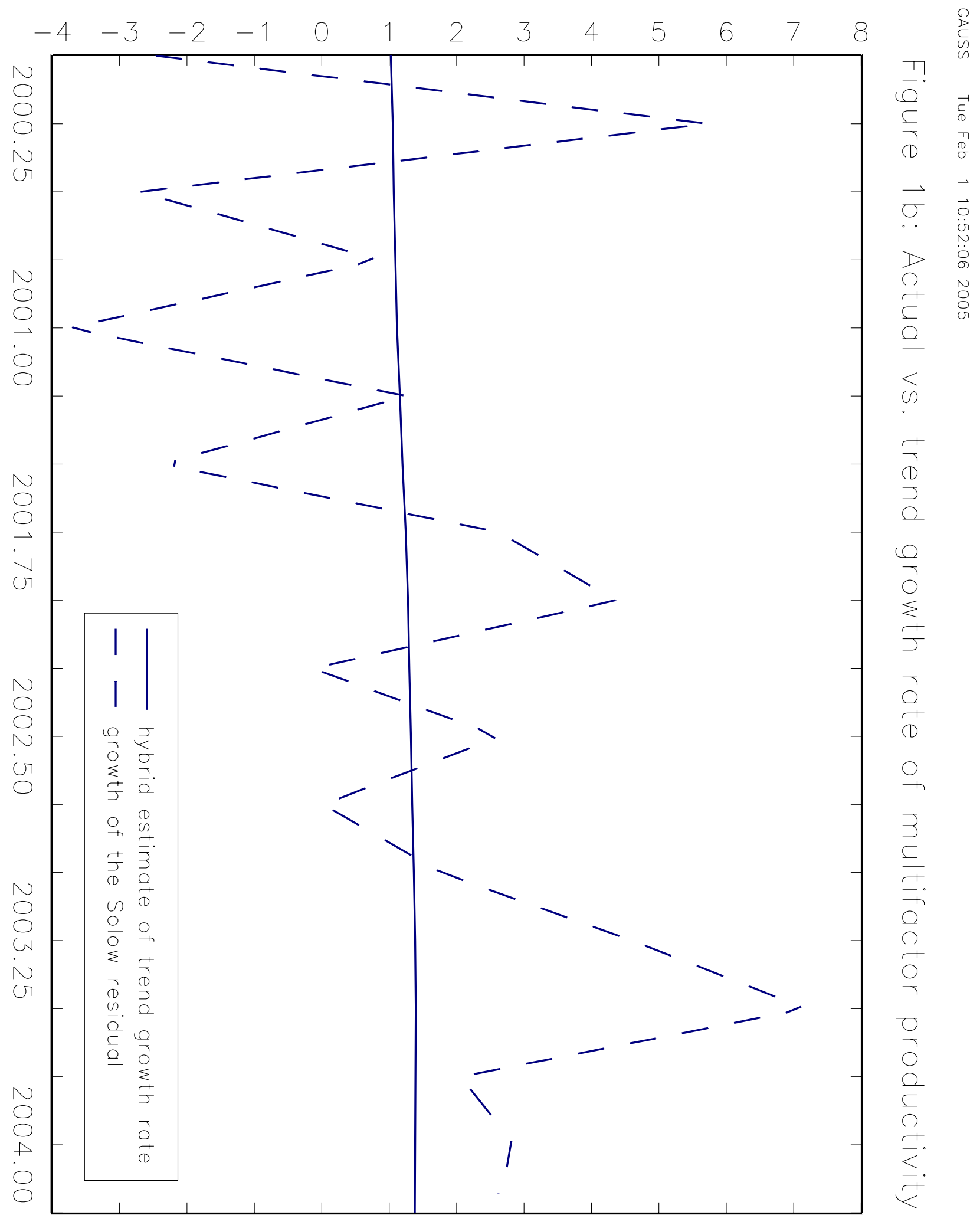




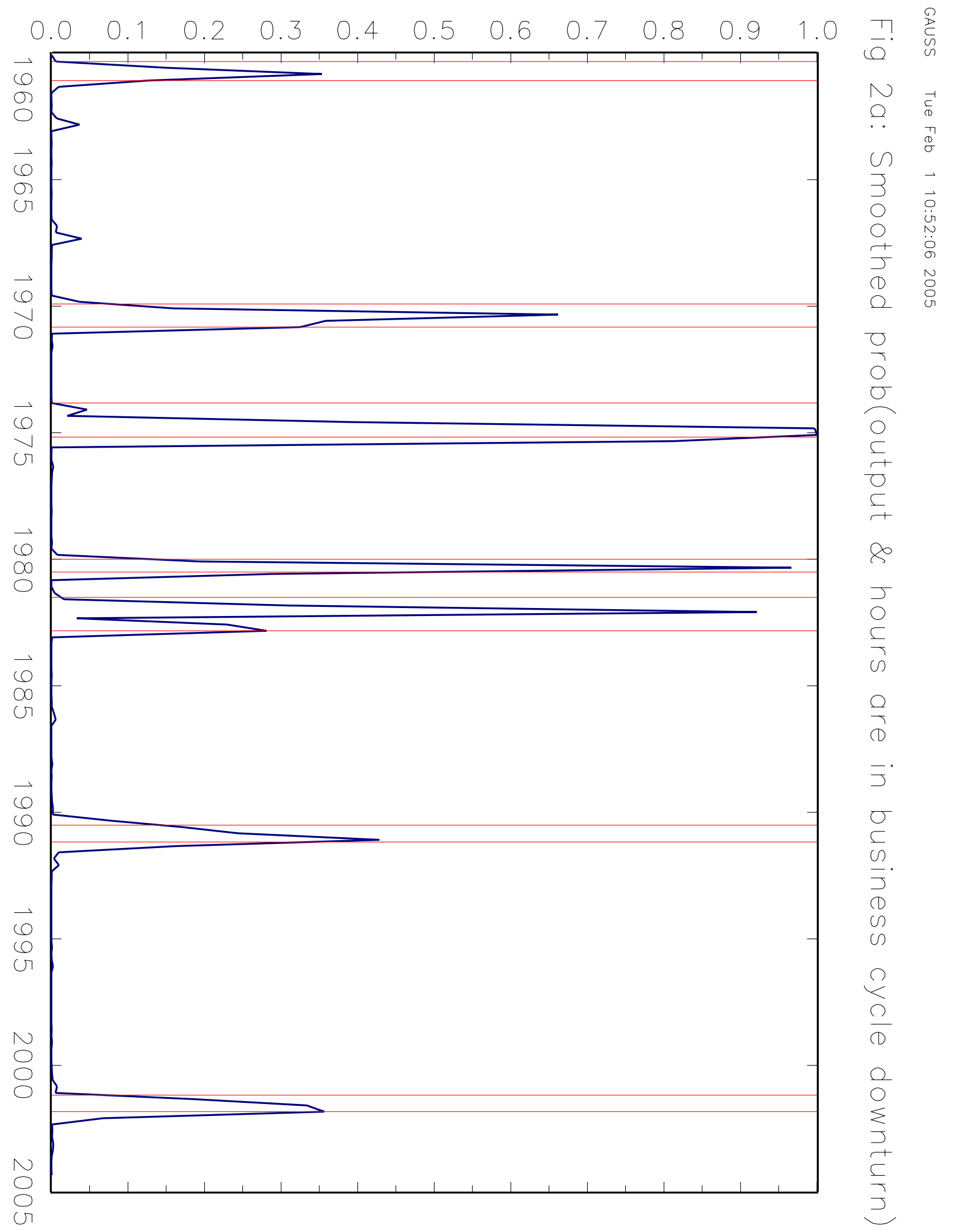




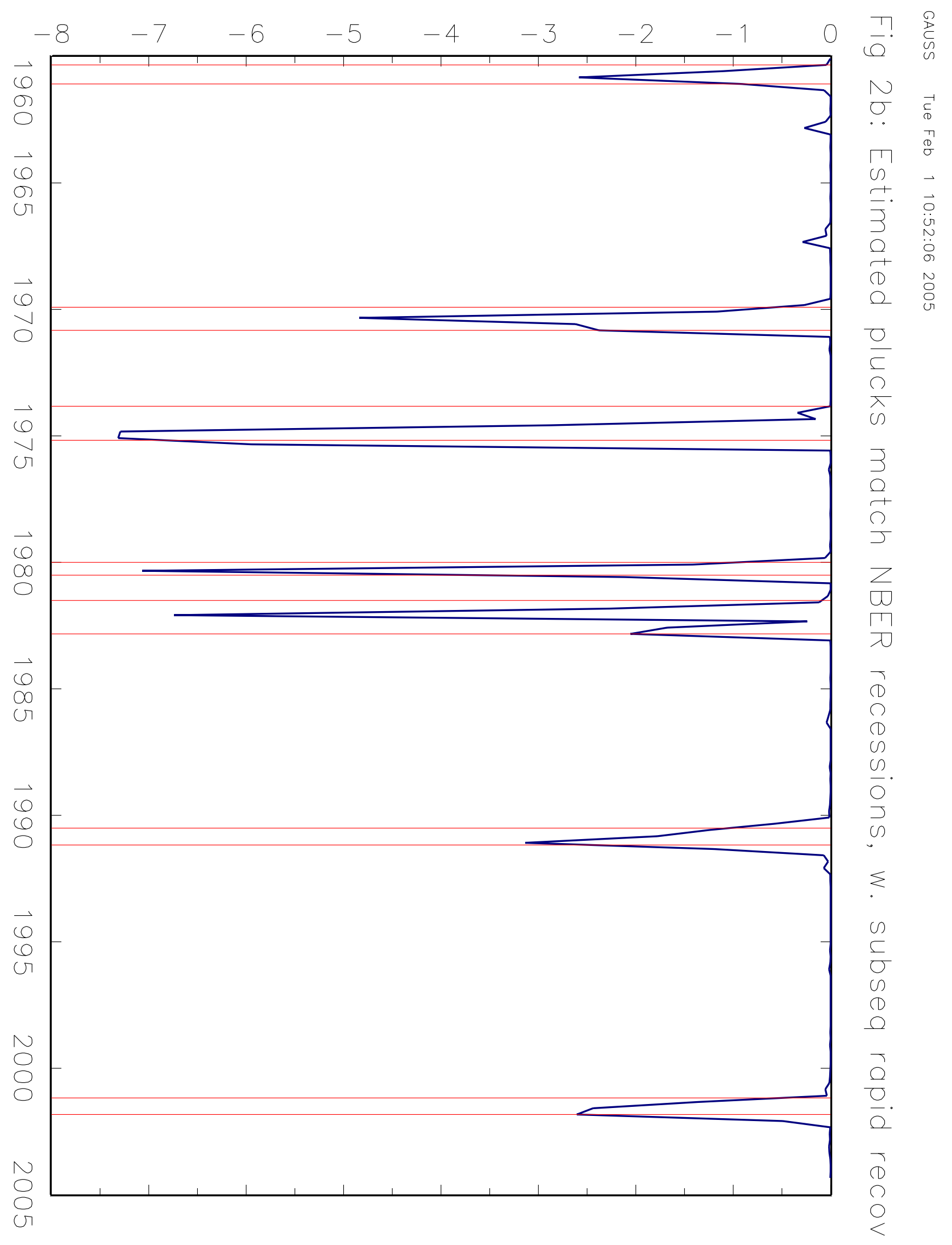




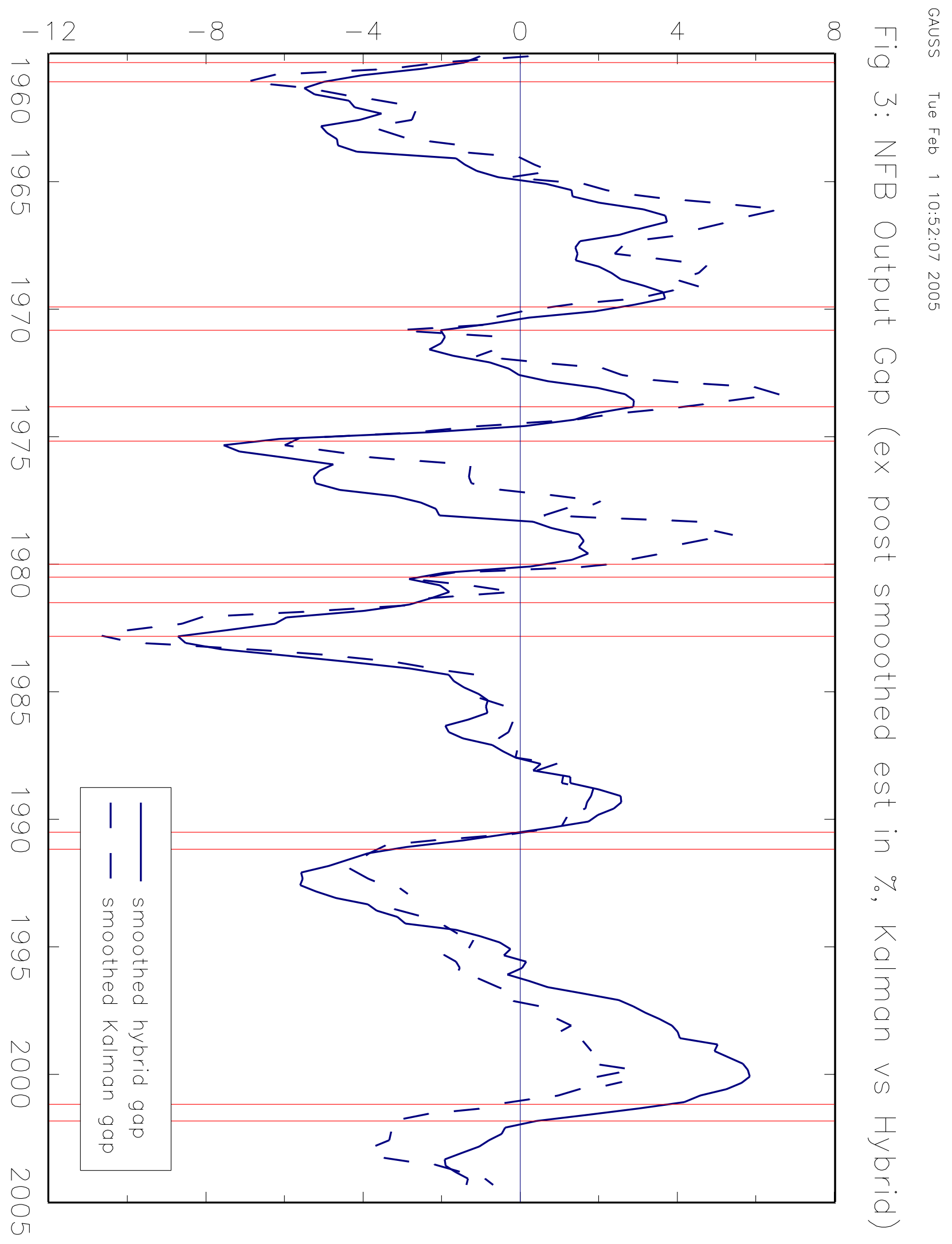




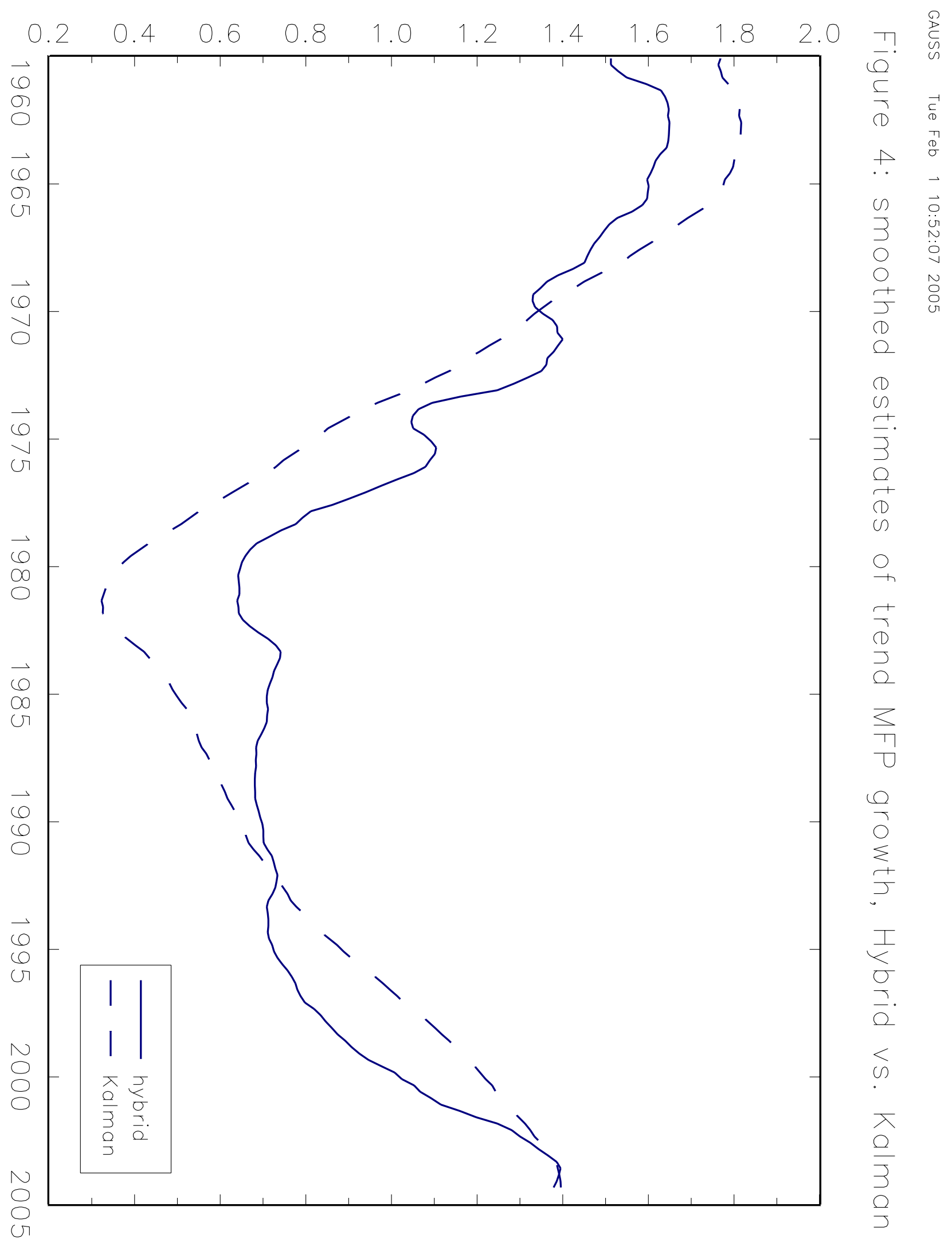




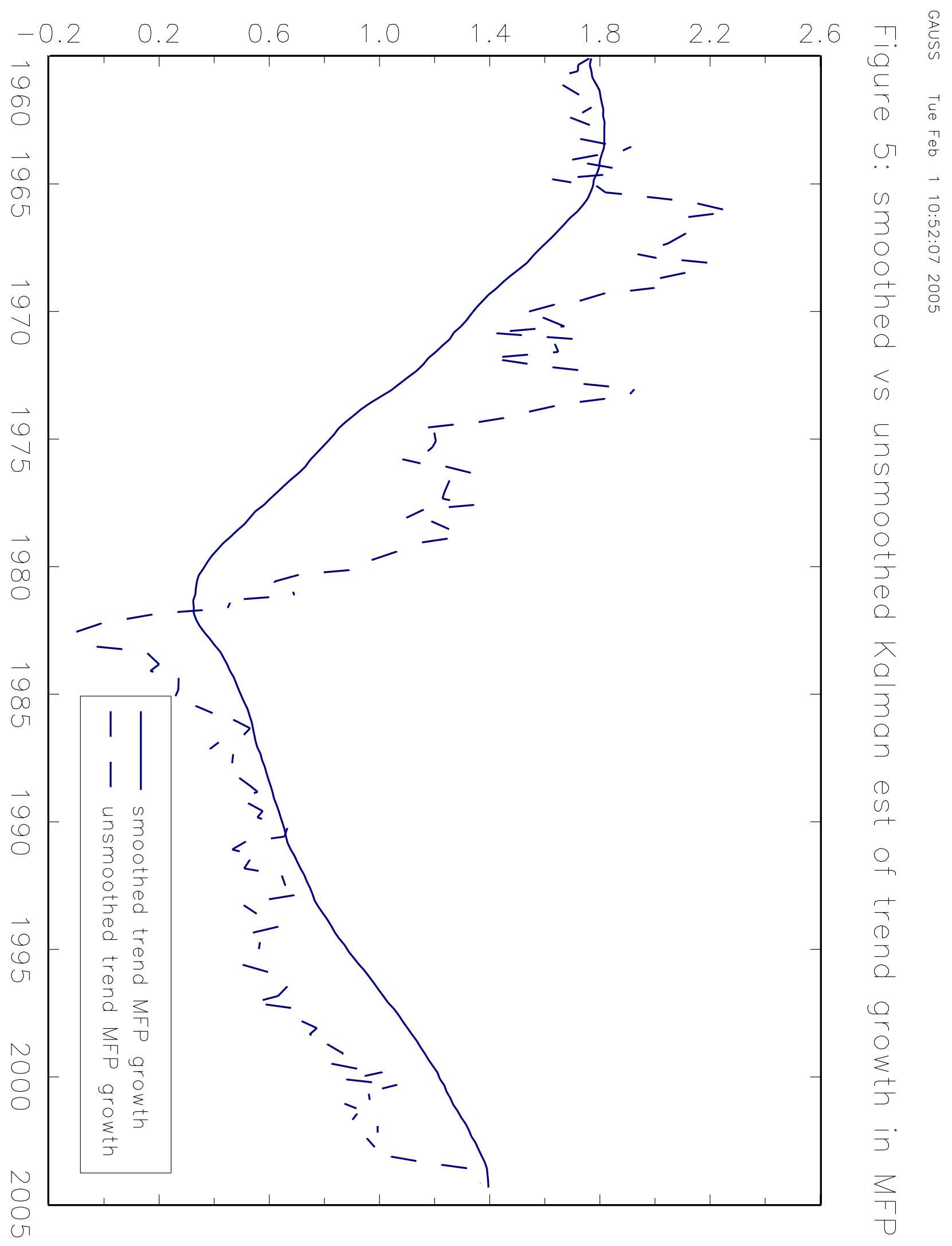




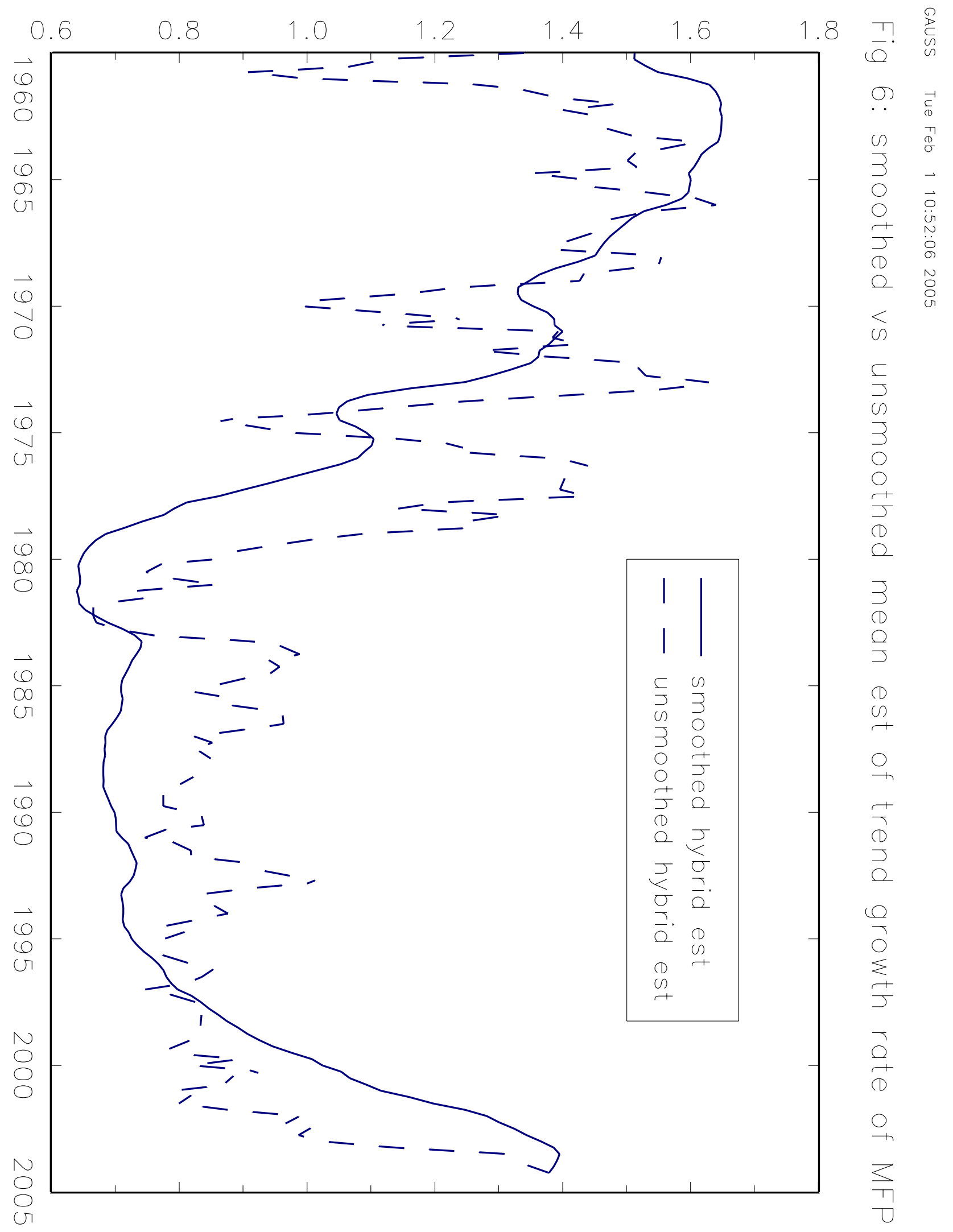




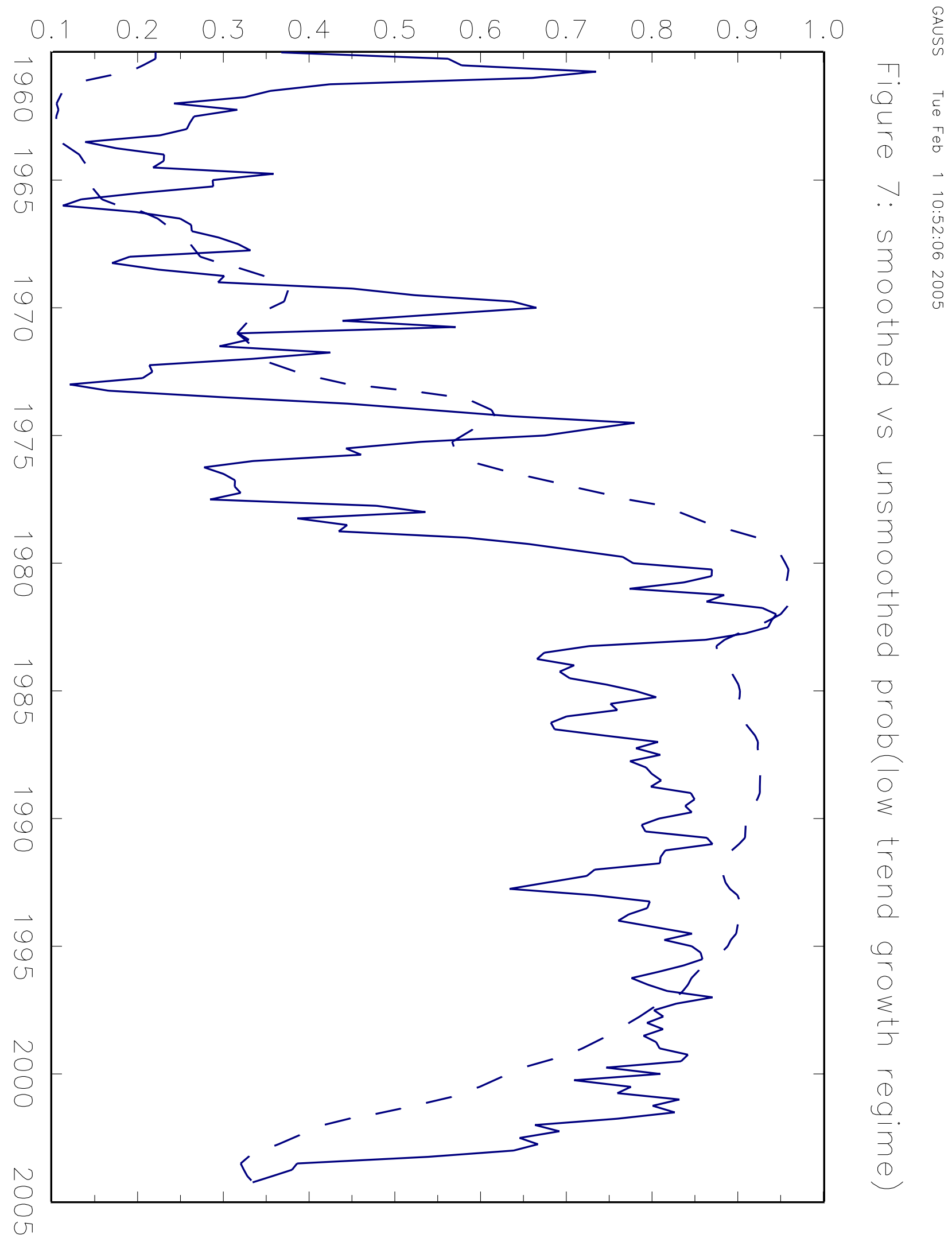

